\title{
On the Nature of the Multivalency Effect: A Thermodynamic Model
}

\author{
Pavel I. Kitov and David R. Bundle \\ Chemistry Department, University of Alberta, Edmonton, Canada T6G 2G2
}

\section{Supporting Information}

\section{Derivation of equation [10]}

The contribution of each bound species to the overall free energy of the system is proportional to the corresponding weight coefficient $\mathrm{w}_{i}$ and free energy of the $i$-th complex. Let us construct a free energy function $\Delta \mathrm{Z}$, which is the weighed sum of those individual contributions:

$\Delta \mathrm{Z}=\sum_{i=1}^{i_{\max }} \mathrm{w}_{i} \Delta \mathrm{G}^{\mathrm{o}}{ }_{i}$

Application of the Gibbs' equation $\mathrm{K}=\exp (-\Delta \mathrm{Z} / \mathrm{RT})$ to this free energy function gives an exponential expression for the arbitrarily constant $\mathrm{K}$. Expansion of the exponent of a sum affords a product of exponents. It is convenient also to take the weight coefficients $\mathrm{w}_{i}$ outside the brackets

$\mathrm{K}=\mathrm{e}^{-\sum_{i=1}^{i_{\max }} \frac{\mathrm{W}_{i} \Delta \mathrm{G}_{i}^{\mathrm{O}}}{\mathrm{RT}}}=\prod_{i=1}^{i_{\max }}\left(\mathrm{e}^{-\frac{\Delta \mathrm{G}}{\mathrm{RT}}}\right)^{\mathrm{w}_{i}}$

The expression in brackets is the definition for the equilibrium constant of $i$-th complex formation, hence

$\mathrm{K}=\prod_{i=1}^{i_{\max }} \mathrm{K}_{i} \mathrm{~W}_{i}=\prod_{i=1}^{i_{\max }}\left(\frac{\left[\mathrm{RL}_{i}\right]}{[\mathrm{R}][\mathrm{L}]}\right)^{\mathrm{W}_{i}}$

Separation of the numerator and denominator in brackets converts the formula into a quotient

$$
\mathrm{K}=\frac{\prod_{i=1}^{i_{\max }}\left[\mathrm{RL}_{i}\right]^{\mathrm{W}_{i}}}{\prod_{i=1}^{i_{\max }}([\mathrm{R}][\mathrm{L}])^{\mathrm{W}_{i}}}
$$

Collection of all exponential indices $\mathrm{w}_{i}$ in the denominator into a sum, which is equal to unity from the definition of weight coefficients $\left(\Sigma \mathrm{w}_{i}=1\right)$, gives

$$
\mathrm{K}=\frac{\prod_{i=1}^{i_{\max }}\left[\mathrm{RL}_{i}\right]^{\mathrm{w}_{i}}}{([\mathrm{R}][\mathrm{L}])^{i_{\max }} \mathrm{w}_{i}}=\frac{\prod_{i=1}^{i_{\max }}\left[\mathrm{RL}_{i}\right]^{\mathrm{w}_{i}}}{[\mathrm{R}][\mathrm{L}]}
$$

Since $\mathrm{w}_{i}$ is the proportionality coefficient between the concentration of the $i$-th complex and the total concentration of bound forms of the receptor i.e. $\left[\mathrm{RL}_{i}\right]=\mathrm{w}_{i} \Sigma\left[\mathrm{RL}_{i}\right]$, after substitution, we obtain

$$
\mathrm{K}=\frac{\prod_{i=1}^{i_{\max }}\left(\mathrm{w}_{i} \sum_{i=1}^{i_{\max }}\left[\mathrm{RL}_{i}\right]\right)^{\mathrm{w}_{i}}}{[\mathrm{R}][\mathrm{L}]}
$$

Separation of the factors in brackets gives

$\mathrm{K}=\prod_{i=1}^{i_{\max }} \mathrm{w}_{i} \mathrm{w}_{i} \frac{\prod_{i=1}^{i_{\max }}\left(\sum_{i=1}^{i_{\max }}\left[\mathrm{RL}_{i}\right]\right)^{\mathrm{w}_{i}}}{[\mathrm{R}][\mathrm{L}]}$ 
The weigh coefficients are collected into the sum:

$\mathrm{K}=\prod_{i=1}^{i_{\max }} \mathrm{w}_{i} \mathrm{w}_{i} \frac{\left(\sum_{i=1}^{i_{\max }}\left[\mathrm{RL}_{i}\right]\right)^{\sum_{i=1}^{i_{\max }} \mathrm{w}_{i}}}{[\mathrm{R}][\mathrm{L}]}$

After taking into account that $\Sigma \mathrm{w}_{i}=1$ we can simplify the expression for $\mathrm{K}$ as follows

$\mathrm{K}=\prod_{i=1}^{i_{\max }} \mathrm{w}_{i} \mathrm{w}_{i} \frac{\sum_{i=1}^{i_{\max }}\left[\mathrm{RL}_{i}\right]}{[\mathrm{R}][\mathrm{L}]}$

The quotient in the final expression is the definition of $\mathrm{K}_{\text {avidity }}$, hence

$\mathrm{K}_{\text {avidity }}=\frac{\mathrm{K}}{\prod_{i=1}^{i_{\max }} \mathrm{w}_{i} \mathrm{w}_{i}}$

or, in energy terms,

$\Delta \mathrm{G}_{\text {avidity }}^{\mathrm{o}}=\sum_{i=1}^{i_{\max }} \mathrm{w}_{i} \Delta \mathrm{G}_{i}+\mathrm{RT} \ln \prod_{i=1}^{i_{\max }} \mathrm{w}_{i}$

Expansion of the latter equation using expression [4] (see the paper) for $\Delta \mathrm{G}_{i}$ gives final expression for avidity binding energy

$\Delta \mathrm{G}_{\text {avidity }}^{\mathrm{o}}=\Delta \mathrm{G}_{\text {inter }}^{\mathrm{o}}+\Delta \mathrm{G}_{\text {intra }}^{\mathrm{o}} \sum_{i=1}^{i_{\max }} \mathrm{w}_{i}(i-1)+\mathrm{RT} \sum_{i=1}^{i_{\max }} \mathrm{w}_{i} \ln \left(\mathrm{w}_{i} / \Omega_{i}\right)$

\section{Derivation of equation [17]}

Consider an interaction between a multivalent receptor presenting $n$ equivalent non-cooperative binding sites and a multivalent ligand presenting $m$ equivalent branches.

$$
\left.\begin{array}{l}
\mathrm{R}+\mathrm{L} \stackrel{\mathrm{K}_{1}^{\prime}}{\rightleftharpoons} \mathrm{RL}_{1} \stackrel{\mathrm{K}_{2}^{\prime}}{\rightleftharpoons} \mathrm{RL}_{2} \rightleftharpoons \ldots \stackrel{\mathrm{K}_{i}^{\prime}}{\rightleftharpoons} \mathrm{RL}_{f} \rightleftharpoons \ldots \\
\left.\mathrm{K}_{1}^{\prime}=\frac{\left[\mathrm{RL}_{1}\right]}{[\mathrm{R}][\mathrm{L}]}=n m \mathrm{k}_{\text {inter }}, \quad \mathrm{K}_{2}^{\prime}=\frac{\left[\mathrm{RL}_{2}\right]}{\left[\mathrm{RL}_{1}\right]}=\frac{(n-1)(m-1)}{2} \mathrm{k}_{\text {intra }}, \ldots\right], \\
\mathrm{K}_{i}^{\prime}=\frac{\left[\mathrm{RL}_{i}\right]}{\left[\mathrm{RL}_{i-1}\right]}=\frac{(n-i+1)(m-i+1)}{i} \mathrm{k}_{\text {intra }}, \ldots,
\end{array}\right\}
$$

where $i$ is the number of occupied binding sites in the complex.

The statistical coefficient of individual binding step $\left(\Omega_{i} / \Omega_{i-1}=\mathrm{F}_{i} / \mathrm{F}_{i-1}\right)$ calculated as a quotient between the number of ways the binding of $i$-th branch occurs $\left(\mathrm{F}_{i}\right)$ and the number of ways the $i$-th branch can dissociate from the product $\left(\mathrm{F}_{i-1}\right)$. For the first step, the statistical coefficient of the direct reaction $\mathrm{F}_{1}=n m$ since the concentration of binding sites is $n$ times higher than that of the receptor $\mathrm{R}$ and the concentration of branches is $m$ times higher than that of the multivalent ligand L. The reverse reaction (dissociation) has only one way to occur, therefore, $\mathrm{F}_{-1}=1$. Analogously, for the $i$-th step, $\mathrm{F}_{i}=(n-i+1)(m-$ $i+1)$ and $\mathrm{F}_{-i}=i$.

Let us write the equilibria as a mathematically equivalent set of parallel reactions, each characterized by a constant of complex formation $\mathrm{K}_{i}$. 
$\mathrm{R}+\mathrm{L} \stackrel{\mathrm{K}_{1}}{\rightleftharpoons} \mathrm{RL} \quad \mathrm{K}_{1}=\mathrm{K}_{1}^{\prime}=\frac{[\mathrm{RL}]}{[\mathrm{R}][\mathrm{L}]}=\mathrm{kF}_{1} / \mathrm{F}_{-1}$

$\mathrm{R}+\mathrm{L} \stackrel{\mathrm{K}_{i}}{\rightleftharpoons} \mathrm{RL}(i) \quad \mathrm{K}_{i}=\mathrm{K}_{1}^{\prime} \mathrm{K}_{2}^{\prime} \ldots \mathrm{K}_{i}^{\prime}=\frac{[\mathrm{RL}(i)]}{[\mathrm{R}][\mathrm{L}]}=\mathrm{k}_{\text {inter }}(i-1) \mathrm{k}_{\text {intra }} \prod_{j=1}^{i} \mathrm{~F}_{j} / \mathrm{F}_{-j}$

The constant of parallel process $\mathrm{K}_{i}$ is the product of constants of all preceding sequential reactions. Hence the statistical coefficient $\Omega_{i}$ is the product of the preceding statistical coefficients

$\Omega_{i}=\prod_{j=1}^{i} \mathrm{~F}_{j} / \mathrm{F}_{-j}=\prod_{j=1}^{i} \frac{(n-j+1)(m-j+1)}{j}$

Using the condition that the maximal number of engaged binding sites $i$ cannot exceed either the number of binding sites $n$ nor the number of branches $m$, we obtain the final expression for the statistical coefficient:

$\Omega_{i}=\frac{n ! m !}{(n-i) !(m-i) ! i !}$

\section{Derivation of equation [20]}

Consider two competitive equilibria, where the ligand of interest L competes for the binding to the same receptor with a labeled ligand $\mathrm{I}$, the indicator:

$$
\begin{aligned}
& \mathrm{R}+\mathrm{L} \stackrel{\mathrm{K}_{\mathrm{L}}}{\rightleftharpoons} \mathrm{RL} \\
& \mathrm{R}+\mathrm{I} \stackrel{\mathrm{K}_{\mathrm{I}}}{\rightleftharpoons} \mathrm{RI}
\end{aligned}
$$

The position of equilibrium in each individual reaction is determined by the corresponding binding constant and standard free energy

$$
\begin{array}{cc}
\mathrm{K}_{\mathrm{L}}=\frac{[\mathrm{RL}]}{[\mathrm{R}][\mathrm{L}]} \quad \Delta \mathrm{G}_{\mathrm{L}}^{\mathrm{o}}=-\mathrm{RT} \ln \mathrm{K}_{\mathrm{L}} \\
\mathrm{K}_{\mathrm{I}}=\frac{[\mathrm{RI}]}{[\mathrm{R}][\mathrm{I}]} \quad \Delta \mathrm{G}_{\mathrm{I}}^{\mathrm{o}}=-\mathrm{RT} \ln \mathrm{K}_{\mathrm{I}}
\end{array}
$$

Let us rewrite the expressions for binding constants as ratios between a complex and free receptor.

$$
\begin{array}{ll}
\underline{\mathrm{K}}_{\mathrm{L}}=\mathrm{K}_{\mathrm{L}}[\mathrm{L}]=\frac{[\mathrm{RL}]}{[\mathrm{R}]} \quad \Delta \underline{\mathrm{G}}_{\mathrm{L}}=-\mathrm{RT} \ln \underline{\mathrm{K}}_{\mathrm{L}} \\
\underline{\mathrm{K}}_{\mathrm{I}}=\mathrm{K}_{\mathrm{I}}[\mathrm{I}]=\frac{[\mathrm{RL}]}{[\mathrm{R}]} \quad \Delta \underline{\mathrm{G}}_{\mathrm{I}}=-\mathrm{RT} \ln \underline{\mathrm{K}}_{\mathrm{I}}
\end{array}
$$

We may term these new parameters $\underline{K}_{L}$ and $\underline{K}_{I}$ "distribution binding constants". They are no longer the standard equilibrium constants but functions of [L]. The corresponding free energy terms, the "distribution free energies", $\Delta \mathrm{G}_{\mathrm{L}}$ and $\Delta \mathrm{G}_{\mathrm{I}}$ are no longer standard free energies but free energies at the particular concentrations of $\mathrm{L}$ and I. In contrast to the standard free energy this parameter has the advantage of being a direct measure of the distribution between different forms of receptor, each located on its respective distribution energy level. We can now construct a partition function for all forms of the receptor and apply the Boltzmann's distribution law in order to find the molar fraction of any form of the receptor. The molar fraction of a complex $\mathrm{w}_{i}$ is given as a normalized Boltzmann's factor:

$$
w_{R}=\frac{1}{1+e^{-\Delta \underline{G} / R T}+e^{-\Delta \underline{G}_{L} / R T}}
$$




$$
\begin{aligned}
& w_{R L}=\frac{e^{-\Delta \underline{G}_{L} / R T}}{1+e^{-\Delta \underline{G}_{1} / R T}+e^{-\Delta \underline{G}_{L} / R T}} \\
& w_{R I}=\frac{e^{-\Delta \underline{G}_{/} / R T}}{1+e^{-\Delta \underline{G}_{1} / R T}+e^{-\Delta \underline{G}_{L} / R T}}
\end{aligned}
$$

Since the complex RI produces the signal which is used to monitor binding we are most interested in the latter expression. Conversion of exponents back into binding constants gives

$$
\mathrm{w}_{\mathrm{RI}}=\frac{\mathrm{K}_{\mathrm{l}}[\mathrm{l}]}{1+\mathrm{K}_{\mathrm{l}}[\mathrm{l}]+\mathrm{K}_{\mathrm{L}}[\mathrm{L}]}
$$

The maximal $\mathrm{w}_{\mathrm{RI}}$ can be achieved at $[\mathrm{L}]=0$

$\mathrm{W}_{\mathrm{RI}}([\mathrm{L}]=0)=\frac{\mathrm{K}_{\mathrm{l}}[\mathrm{l}]}{1+\mathrm{K}_{\mathrm{I}}[\mathrm{I}]}$

At the midpoint of the binding isotherm, where $[\mathrm{L}]=\mathrm{IC}_{50}, \mathrm{w}_{\mathrm{RI}}$ is half of the maximum. Hence

$\frac{\mathrm{K}_{\mathrm{I}}[\mathrm{l}]}{2+2 \mathrm{~K}_{\mathrm{I}}[\mathrm{l}]}=\frac{\mathrm{K}_{\mathrm{I}}[\mathrm{l}]}{1+\mathrm{K}_{\mathrm{I}}[\mathrm{l}]+\mathrm{K}_{\mathrm{L}} \mathrm{IC}_{50}}$

Simplification of the latter gives

$\mathrm{IC}_{50}=\frac{1+\mathrm{K}_{\mathrm{I}}[\mathrm{l}]}{\mathrm{K}_{\mathrm{L}}}$

\section{Derivation of equation [21]}

Consider an interaction between a multivalent receptor presenting $n$ equivalent non-cooperative binding sites and a monovalent ligand. The independent binding sites are sequentially filled with ligands.

$$
\begin{array}{ll}
\mathrm{R}+\mathrm{L} \stackrel{\mathrm{K}_{1}}{\rightleftharpoons} \mathrm{RL} & \mathrm{K}_{1}=\frac{[\mathrm{RL}]}{[\mathrm{R}][\mathrm{L}]}=\mathrm{kF}_{1} / \mathrm{F}_{-1} \\
\mathrm{RL}_{i-1}+\mathrm{L} \stackrel{\mathrm{K}_{i}}{\rightleftharpoons} \mathrm{RL}_{i} & \mathrm{~K}_{i}=\frac{\left[\mathrm{RL}_{i}\right]}{\left[\mathrm{RL}_{i-1}\right][\mathrm{L}]}=\mathrm{kF}_{i} / \mathrm{F}_{-i}
\end{array}
$$

The macroscopic constant of each consecutive reaction $\mathrm{K}_{i}$ is proportional to the intrinsic binding constant $\mathrm{k}$. The proportionality coefficient is the quotient between statistical factors for direct and reverse reactions $\left(\mathrm{F}_{i}\right.$ and $\left.\mathrm{F}_{-}\right)$. For the first step, $\mathrm{F}_{1}=n$ since the probability of the interaction is $\mathrm{n}$ times greater then for monovalent interaction, $\mathrm{F}_{-1}=1$ since there is only one way to dissociate one ligand from the complex. Analogously, for the $i$-th step, $\mathrm{F}_{i}=(n-i+1)$ and $\mathrm{F}_{-i}=i$.

Let us write the equilibria as a mathematically equivalent set of parallel reactions each characterized by a constant of complex formation $\mathrm{K}_{i}$.

$$
\begin{aligned}
& \mathrm{R}+\mathrm{L} \stackrel{\mathrm{K}_{1}^{\prime}}{\rightleftharpoons} \mathrm{RL} \quad \mathrm{K}_{1}^{\prime}=\mathrm{K}_{1}=\frac{[\mathrm{RL}]}{[\mathrm{R}][\mathrm{L}]}=\mathrm{kF}_{1} / \mathrm{F}_{-1} \\
& \mathrm{R}+i \mathrm{~L} \stackrel{\mathrm{K}_{i}^{\prime}}{\rightleftharpoons} \mathrm{RL}_{i} \quad \mathrm{~K}_{i}^{\prime}=\mathrm{K}_{1} \mathrm{~K}_{2} \ldots \mathrm{K}_{i}=\frac{\left[\mathrm{RL}_{i}\right]}{[\mathrm{R}][\mathrm{L}]^{i}}=\mathrm{k}^{i} \prod_{j=1}^{i} \mathrm{~F}_{j} / \mathrm{F}_{-j}
\end{aligned}
$$

The constant of parallel process $\mathrm{K}^{\prime}$ is the product of constants of all preceding sequential reactions. Hence the statistical coefficient $\Omega_{i}$ is the product of the preceding statistical coefficients

$$
\Omega_{i}=\prod_{j=1}^{i} \mathrm{~F}_{j} / \mathrm{F}_{-j}=\prod_{j=1}^{i}(n-j+1) / j
$$

Taking into account that the number of occupied binding sites $i$ cannot exceed the total number of binding sites $n$ we find that the statistical coefficient is equal to binomial coefficient. 
$\Omega_{i}=\frac{n !}{(n-i) ! i !}$

Let us rewrite the equilibria equations as ratios between a complex and free receptor:

$$
\begin{aligned}
& \mathrm{R} \rightleftharpoons \mathrm{RL} \quad \frac{[\mathrm{RL}]}{[\mathrm{R}]}=\mathrm{k}[\mathrm{L}] \Omega_{1} \\
& \mathrm{R} \rightleftharpoons \mathrm{RL}_{i} \frac{\left[\mathrm{RL} \mathrm{L}_{i}\right]}{[\mathrm{R}]}=\mathrm{k}^{i}[\mathrm{~L}]^{i} \Omega_{i}
\end{aligned}
$$

It is convenient to assign this ratio a name distribution binding constant $\underline{\mathrm{K}}_{i}$ and call the corresponding energy the distribution free energy of the $i$-th complex, $\Delta \underline{\mathrm{G}}_{i}=i(\Delta \mathrm{G}-\mathrm{RT} \ln [\mathrm{L}])-\mathrm{RT} \ln \Omega_{i .} \mathrm{In}$ contrast with standard free energy, the $\Delta \underline{G}_{i}$ has the advantage of being direct measure of the distribution between different forms of receptor, each located on its respective distribution energy level. In order to describe the isothermal equilibrium distribution of receptor species we need to construct a partition function

$$
\text { Partition }=\sum_{i=0}^{n} \mathrm{e}^{-\Delta \underline{\mathrm{G}} / \mathrm{RT}}=\sum_{i=0}^{n} \Omega_{i}([\mathrm{~L}] \mathrm{k})^{i}
$$

The multivalent binding model described above can easily be modified in order to describe competitive equilibrium. In a competitive inhibition assay, the receptor interacts not only with the ligand L, called "inhibitor", but also with a reference molecule I, called "indicator", and the latter interaction should produce a detectable signal. Hence, the equilibria equations [14]-[18] must be modified to include these additional equilibria with I. Let us also assume that the indicator can only react with free receptor and does not detect complexes $\mathrm{RL}_{i}$. Hence the interaction with indicator generates an independent bound state RI with the corresponding binding constant $\mathrm{k}_{\mathrm{RI}}$ and free energy $\Delta \mathrm{G}_{\mathrm{RI}}^{\mathrm{o}}$. After conversion of standard free energy to the distribution free energy, we may include the bound state RI in the partition function

$$
\begin{aligned}
\text { Partition }= & \sum_{i=0}^{n} e^{-\Delta \underline{G} / R T}+e^{-\Delta \underline{G}_{R} / R T} \\
& =\sum_{i=0}^{n} \Omega_{i}([L] k)^{i}+[l] k_{\mathrm{RI}}
\end{aligned}
$$

The partition function permits us to find the molar fraction of RI, which is used for monitoring the inhibition, i.e. to derive the expression for inhibition isotherm

$$
\mathrm{w}_{\mathrm{RI}}=\frac{[\mathrm{l}] \mathrm{k}_{\mathrm{Rl}}}{\sum_{i=0}^{n} \Omega_{i}([\mathrm{~L}] \mathrm{k})^{i}+[\mathrm{l}] \mathrm{k}_{\mathrm{Rl}}}
$$

This isotherm will asymptotically approach zero at high $[\mathrm{L}]$ and $\mathrm{w}_{\mathrm{RI}}$ equals to $[\mathrm{I}] \mathrm{k}_{\mathrm{RI}} /\left(1+[\mathrm{I}] \mathrm{k}_{\mathrm{RI}}\right)$ when no ligand is added. Hence at the midpoint of inhibition curve where $\mathrm{w}_{\mathrm{RI}}=0.5[\mathrm{I}] \mathrm{k}_{\mathrm{RI}} /\left(1+[\mathrm{I}] \mathrm{k}_{\mathrm{RI}}\right)$ and $[\mathrm{L}]=$ $\mathrm{IC}_{50}$

$$
\frac{{ }^{[l] \mathrm{k}_{\mathrm{RI}}}}{2+2[\mathrm{l}] \mathrm{k}_{\mathrm{RI}}}=\frac{[\mathrm{l}] \mathrm{k}_{\mathrm{RI}}}{\sum_{i=0}^{n} \Omega_{i}([\mathrm{~L}] \mathrm{k})^{i}+[l] \mathrm{k}_{\mathrm{Rl}}}
$$

$\sum_{i=0}^{n} \Omega_{i}\left(I C_{50} k\right)^{i}=2+[1] \mathrm{k}_{\mathrm{RI}}$

Taking into account that $\Omega_{i}$ is the binomial coefficient and applying binomial theorem to the left side of the equation we obtain

$\left(1+I C_{50} k\right)^{n}=2+[I] k_{R I}$

and finally 
$\mathrm{IC}_{50}=\frac{\sqrt[n]{2+[\mathrm{l}] \mathrm{k}_{\mathrm{RI}}}-1}{\mathrm{k}}$ 


\section{MAPLE program for $\chi^{2}$ minimization}

The mathematical suit MAPLE 5.1 (Waterloo Maple Inc., 57 Erb Street West, Waterloo,Ontario, Canada N2L 6C2, www.maplesoft.com) was used for all calculations included in the manuscript.

The following program requires input of experimental $\Delta \mathrm{g}_{\text {avidity }}$ values for a set of analogous ligands (values $\mathrm{A}\left[\mathrm{n}, \mathrm{m}, \mathrm{f}_{\max }\right]$ ) and returns minimal $\chi^{2}, \Delta \mathrm{G}_{\text {inter }}$ and $\Delta \mathrm{G}_{\text {intra }}$. The program also creates a text file "avidity", containing matrix of $\chi^{2}$ values. This file can be read in Microsoft Excel, in order to plot the matrix as a surface for visual inspection.

Lines shown in bold should be modified according to the system under study.

restart;

\#INPUT number of steps, mmax number of sites, mmax number of branches;

step:=101:

$\mathrm{CX}:=100000$ :

DG11:=array(1..step,1..step):

DG22:=array(1..step,1..step):

$\mathrm{Z}:=\operatorname{array}(1 .$. step, 1 ..step):

\#INPUT boundary for DG1 and DG2,

DG1min:=-10.:

DG1max:=10.:

DG2min:=-10.:

DG2max:=10.:

DDG1:=(DG1max-DG1min $) /($ step -1$)$ :

DDG2:=(DG2max-DG2min $) /($ step -1$)$ :

\#INPUT points: $A[n, m, f m a x]:=x$;

$A[5,3,3]:=-6.547107701$ :

$A[5,4,4]:=-8.058487878$ :

$\mathrm{A}[5,5,5]:=-9.301681282$ :

for $\mathrm{v}$ from 1 to step do

for vv from 1 to step do

DG11[v,vv]:=DG1min+(v-1)*DDG1:

DG1:=DG11[v,vv]:

DG22[v,vv]:=DG2min+(vv-1)*DDG2:

DG2:=DG22[v,vv]:

$\mathrm{n}:=5: \mathrm{m}:=3: \mathrm{fmax}:=3$ :

$\mathrm{B}[\mathrm{n}, \mathrm{m}, \mathrm{fmax}]:=-0.5961 * \ln (\operatorname{sum}(\exp (-\mathrm{DG} 1 / 0.5961-(\mathrm{f}-1) * \mathrm{DG} 2 / 0.5961+\ln (\mathrm{m} ! * \mathrm{n} ! /((\mathrm{m}-\mathrm{f}) ! *(\mathrm{f} !) *(\mathrm{n}-\mathrm{f}) !)))$, 'f'=1..fmax));

$\mathrm{C} 1:=(\mathrm{A}[\mathrm{n}, \mathrm{m}, \mathrm{fmax}]-\mathrm{B}[\mathrm{n}, \mathrm{m}, \mathrm{fmax}])^{\wedge} 2$;

$\mathrm{n}:=5: \mathrm{m}:=4: \mathbf{f m a x}:=4$ :

$\mathrm{B}[\mathrm{n}, \mathrm{m}, \mathrm{fmax}]:=-0.5961 * \ln (\operatorname{sum}(\exp (-\mathrm{DG} 1 / 0.5961-(\mathrm{f}-1) * \mathrm{DG} 2 / 0.5961+\ln (\mathrm{m} ! * \mathrm{n} ! /((\mathrm{m}-\mathrm{f})$ !*(f!)*(n-f)!)))', ' $\mathrm{f}=1 . .(\mathrm{fmax}))$;

$\mathrm{C} 2:=(\mathrm{A}[\mathrm{n}, \mathrm{m}, \mathrm{fmax}]-\mathrm{B}[\mathrm{n}, \mathrm{m}, \mathrm{fmax}])^{\wedge} 2$;

$\mathrm{n}:=5: \mathrm{m}:=5: \mathbf{f m a x}:=5$ :

$\mathrm{B}[\mathrm{n}, \mathrm{m}, \mathrm{fmax}]:=-0.5961 * \ln (\operatorname{sum}(\exp (-\mathrm{DG} 1 / 0.5961-(\mathrm{f}-1) * \mathrm{DG} 2 / 0.5961+\ln (\mathrm{m} ! * \mathrm{n} ! /((\mathrm{m}-\mathrm{f}) ! *(\mathrm{f} !) *(\mathrm{n}-\mathrm{f}) !)))$, 'f'=1..fmax));

$\mathrm{C} 3:=(\mathrm{A}[\mathrm{n}, \mathrm{m}, \mathrm{fmax}]-\mathrm{B}[\mathrm{n}, \mathrm{m}, \mathrm{fmax}])^{\wedge} 2$;

DG11[v,vv]:=DG1:DG22[v,vv]:=DG2: 


\section{$\mathrm{C}[\mathrm{v}, \mathrm{vv}]:=(\mathrm{C} 1+\mathrm{C} 2+\mathrm{C3}) / 3$;}

if $(\mathrm{C}[\mathrm{v}, \mathrm{vv}]<\mathrm{CX})$ then $\mathrm{CX}:=\mathrm{C}[\mathrm{v}, \mathrm{vv}]$;

G1:=DG1; G2:=DG2;

fi:

od;od;

for $\mathrm{x}$ from 1 to step do

for $y$ from 1 to step do

$\mathrm{Z}[\mathrm{x}, \mathrm{y}]:=\mathrm{C}[\mathrm{x}, \mathrm{y}]$;

od;od;

writedata(avidity,Z):

print("X2=", CX);

print("DGinter=", evalf(G1));

print("DGintra=", evalf(G2)); 
Compound 3

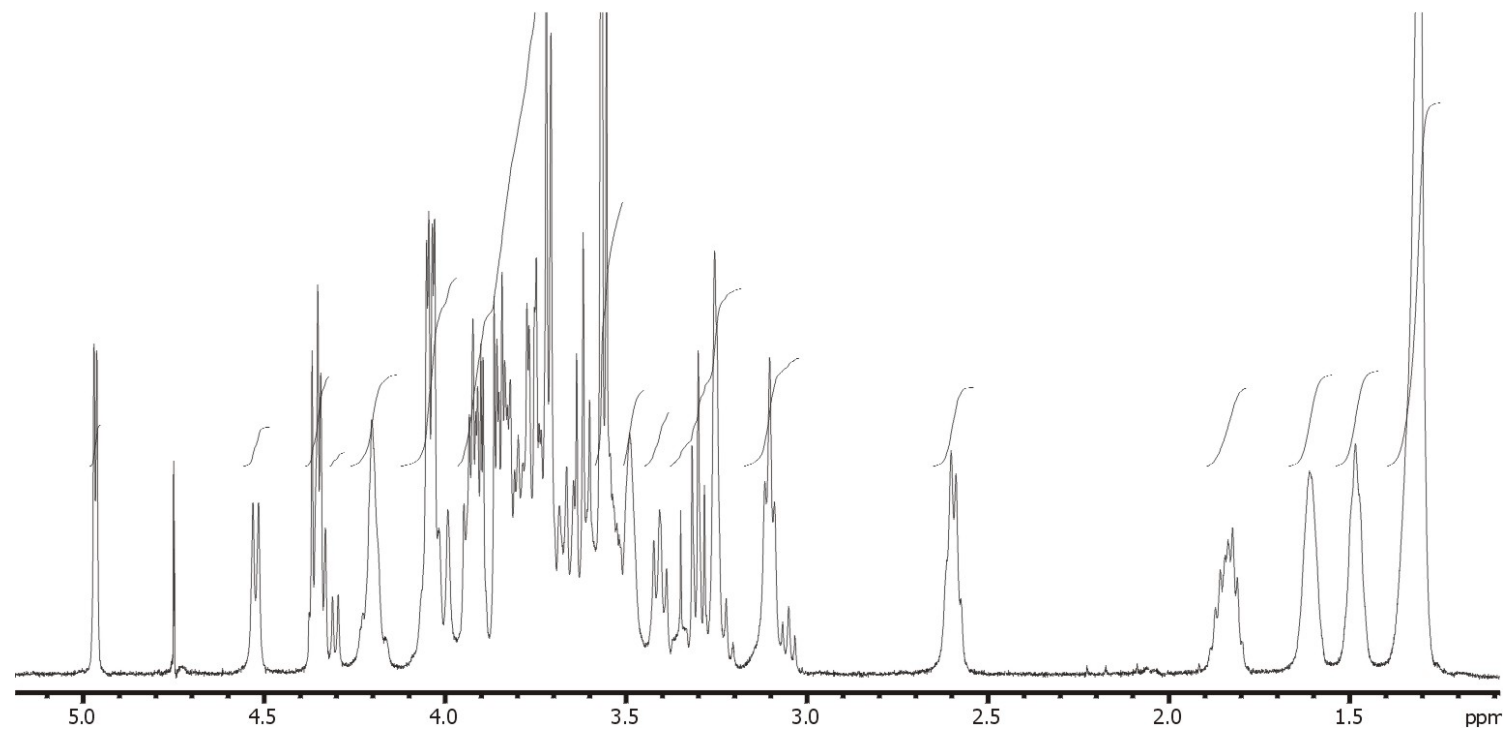

Compound 4

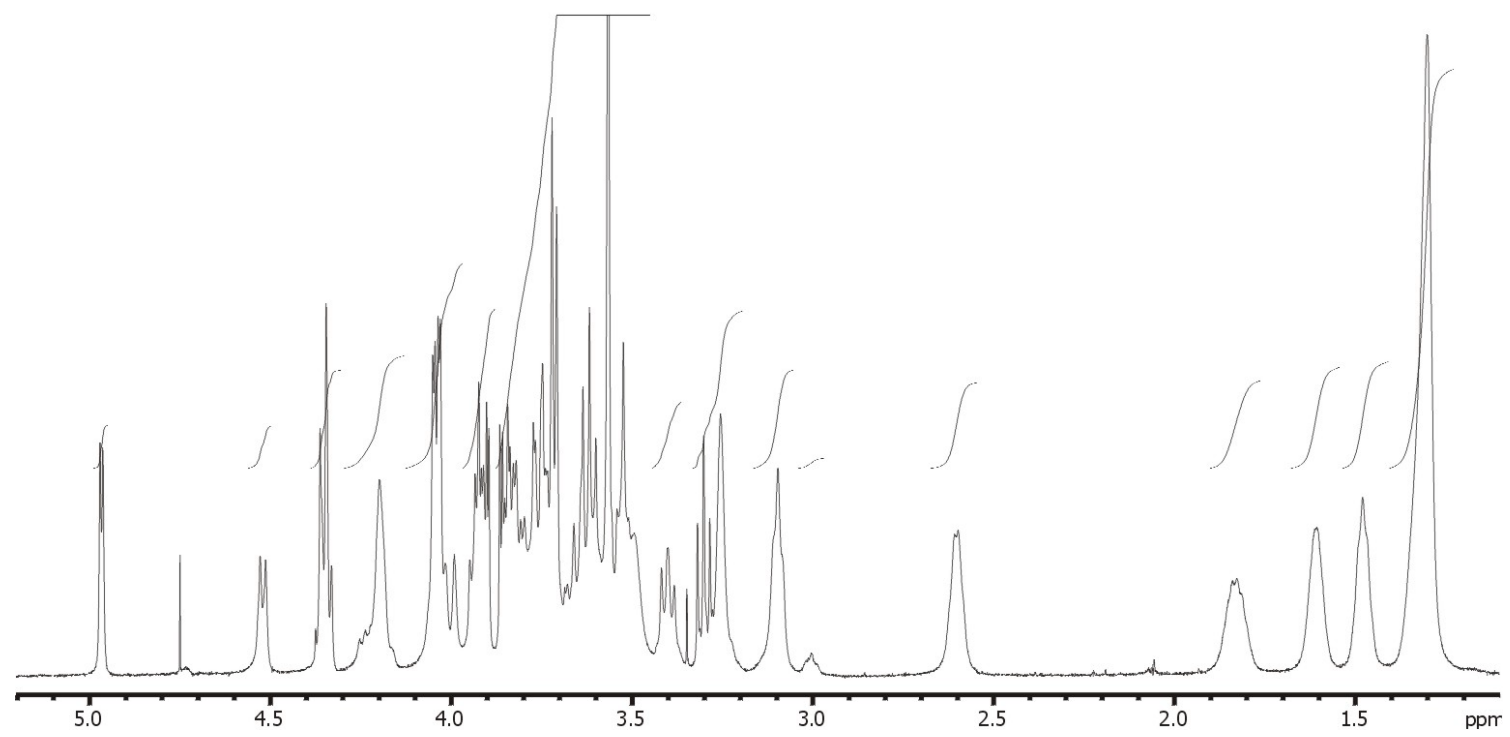


Compound 5

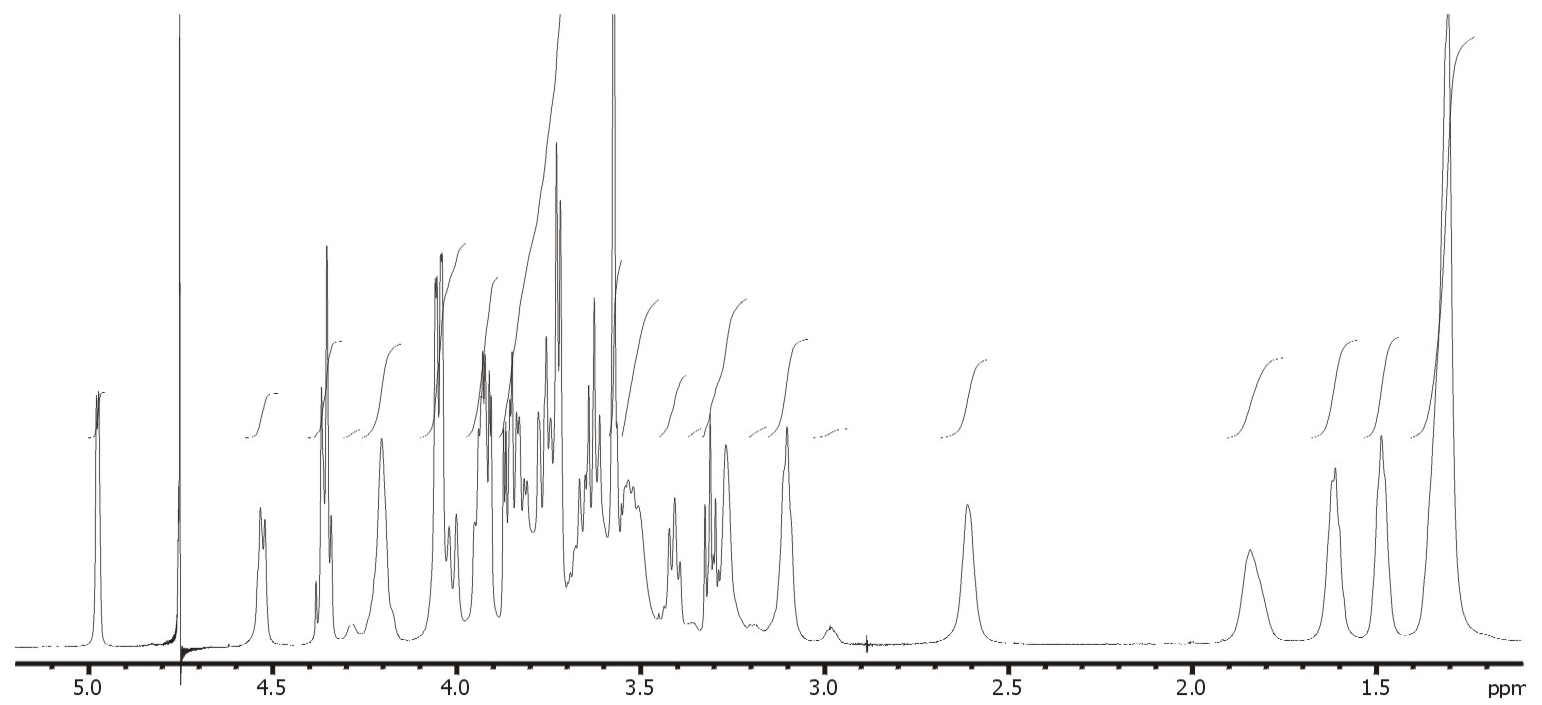

Compound 6

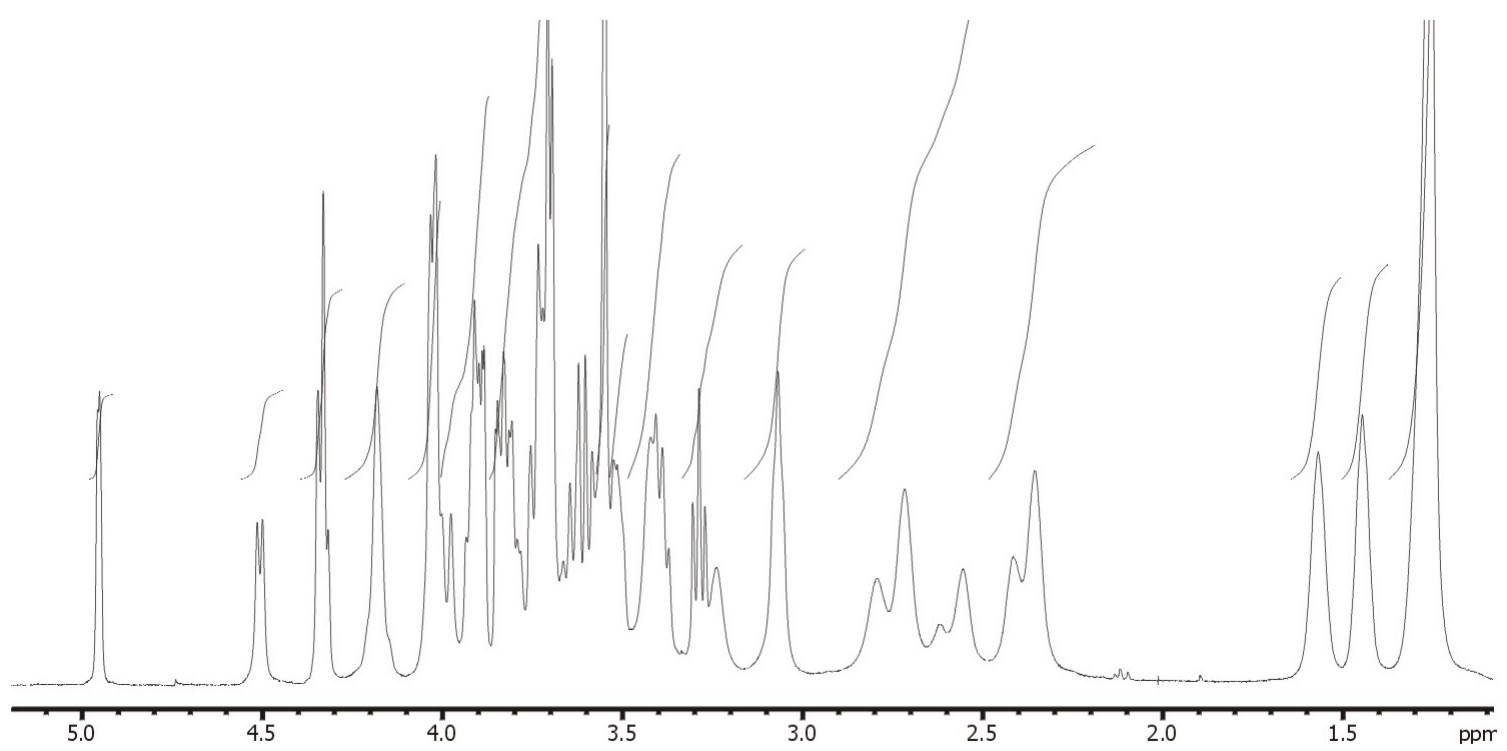




\section{Compound 7}

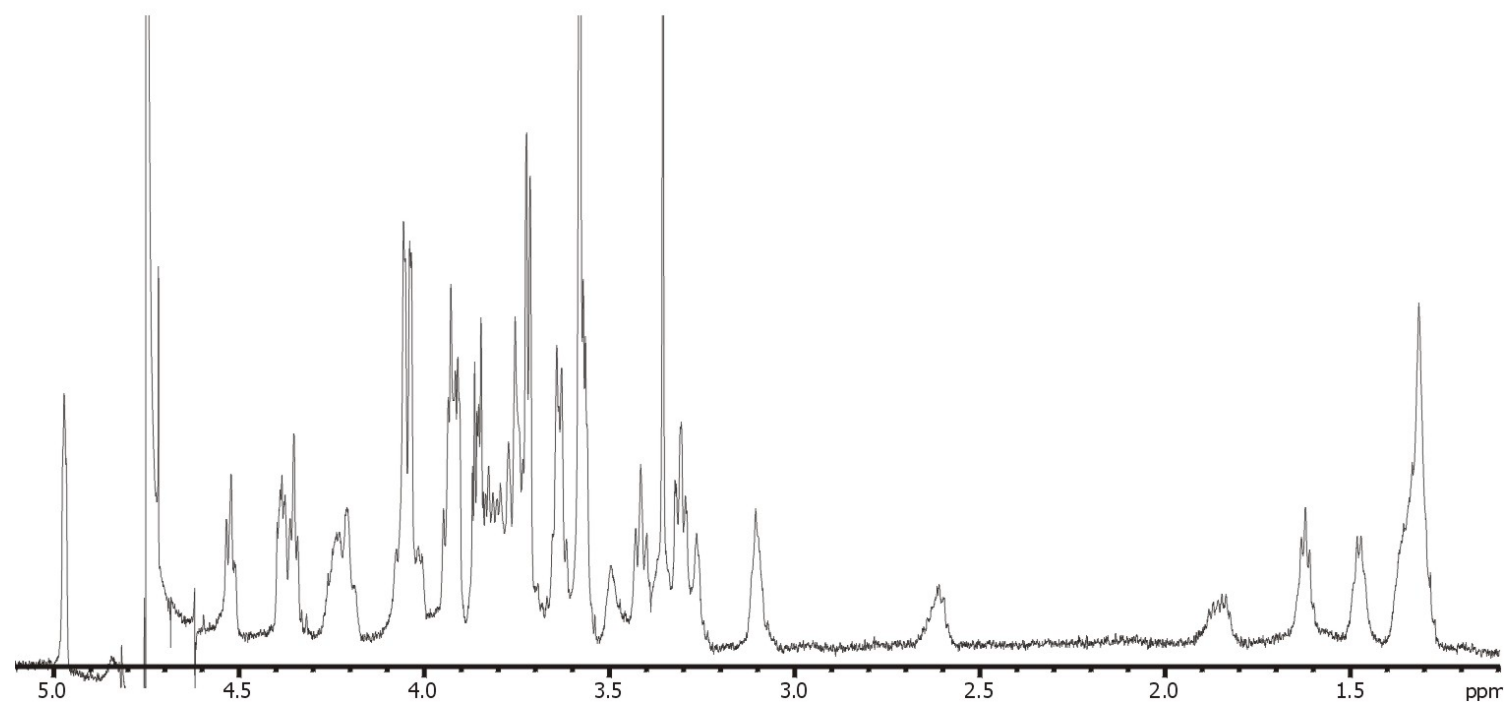

\section{Compound 8}

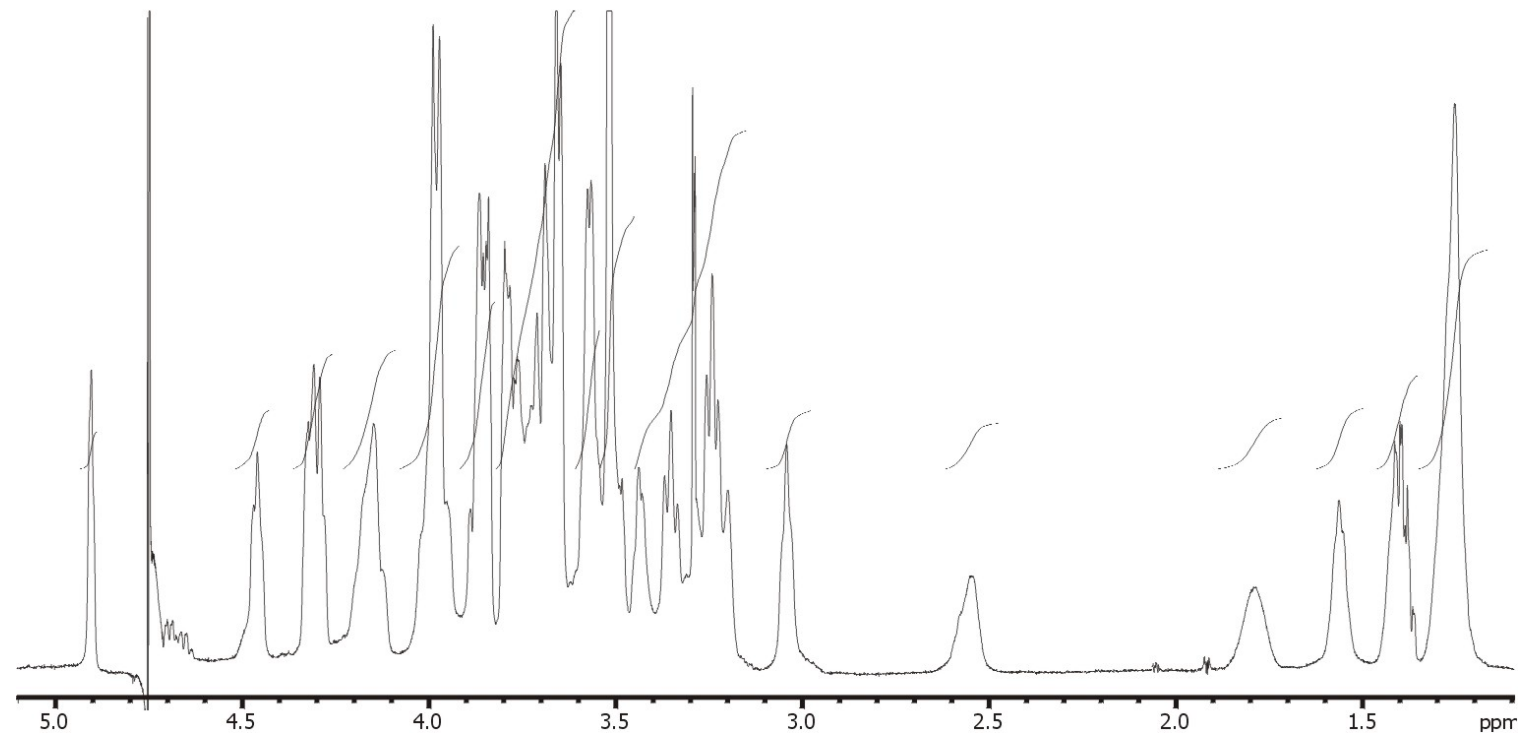




\section{Compound 9}

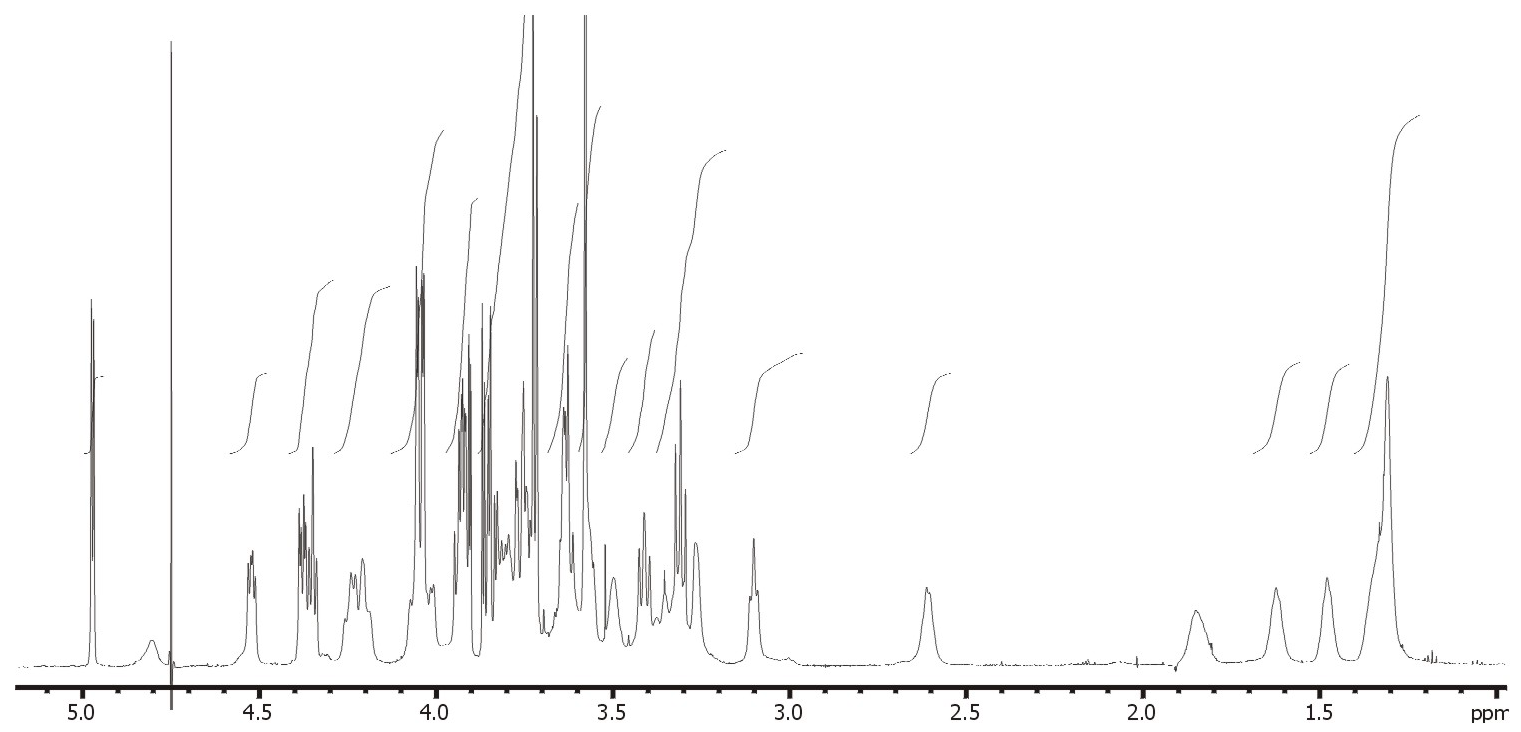

\section{Mass spectrometry data}

\begin{tabular}{|l|l|l|l|}
\hline Compound & MW & $\begin{array}{c}\text { ES deconvolution } \\
\text { of multiple charged } \\
\text { ions }\end{array}$ & MALDI TOF \\
\hline $\mathbf{3}$ & 3149.36 & 3149 & 3146 \\
\hline $\mathbf{4}$ & 4134.42 & 4134 & 4136 \\
\hline $\mathbf{5}$ & 5105.45 & 5105 & 5123 \\
\hline $\mathbf{6}$ & 7916.20 & & 7938 \\
\hline & & & 5274 \\
\hline $\mathbf{7}$ & 5263.25 & 5264 & \\
\hline $\mathbf{8}$ & 6952.93 & 6953 & 8660 \\
\hline $\mathbf{9}$ & 8628.59 & 8630 & \\
\hline
\end{tabular}

